DOI 10.15517/revenf.v0i40.41903

\title{
Experiências durante a internação de um recém-nascido prematuro em terapia intensiva ${ }^{1}$ Experiences during the hospitalization of a premature newborn under intensive care Experiencias durante la hospitalización de recién nacido prematuro bajo atención intensiva
}

Luciano Marques dos Santos², Gabriela Santos Silva ${ }^{3}$, Laís da Silva Santana ${ }^{4}$, Marialda Moreira Christoffel ${ }^{5}$, Elenice Valentim Carmona ${ }^{6}$, Silvia da Silva Santos Passos ${ }^{7}$

\section{RESUMO}

Objetivo: Compreender a experiência do pai e da família ampliada durante a hospitalização do recémnascido prematuro em Unidade de Terapia Intensiva Neonatal. Método: Pesquisa qualitativa, descritiva e exploratória, realizada em uma maternidade pública de grande porte na cidade de Feira de Santana, Bahia, Brasil. Os dados foram colhidos por meio de entrevistas semiestruturadas, que foram gravadas em áudio e, posteriormente, analisados segundo a Análise de Conteúdo Temática. Resultados: A partir das falas de 16 participantes, foram desveladas quatro categorias temáticas: Uma experiência inicialmente marcada pelo sofrimento; uma experiência difícil na rotina da família; buscando se fortalecer ao longo da experiência e sentindo-se mais tranquilos ao longo da experiência. Conclusão: a experiência foi marcada por alterações impactantes em domínios de funcionamento familiar, considerando aspectos cognitivos, afetivos e comportamentais, demonstrando a necessidade de cuidado que contemple de forma intencional a família no contexto pesquisado, bem como implementação e acompanhamento da abordagem recomendada pelo cuidado centrado no recém-nascido e sua família.

Palavras-chave: Enfermagem Neonatal; Família; Pesquisa qualitativa; Prematuro; Unidades de Terapia Intensiva Neonatal.

\footnotetext{
${ }^{1}$ Data de recebimento: 19 de maio de 2020

Data de aceitação: 09 de outubro de 2020

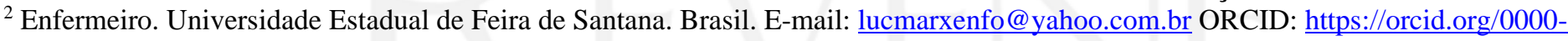
0001-7866-6353

${ }^{3}$ Enfermeira. Universidade Estadual de Feira de Santana. Brasil. E-mail: gabisilva93@ hotmail.com ORCID: https://orcid.org/00000003-1895-282X

${ }^{4}$ Enfermeira. Universidade Estadual de Feira de Santana. Brasil. E-mail: laissantanaenf@ gmail.com ORCID: https://orcid.org/00000002-8755-6962

${ }^{5}$ Enfermeira. Universidade Federal do Rio de Janeiro. Brasil. E-mail: marialdanit@ gmail.com ORCID: https://orcid.org/0000-0003$2255-949$

${ }^{6}$ Enfermeira. Universidade Estadual de Campinas. Brasil. E-mail: elenicevalentim@ uol.com.br ORCID: https://orcid.org/0000-00019976-3603

${ }^{7}$ Enfermeira. Universidade Estadual de Feira de Santana. Brasil. E-mail: ssspassos@ yahoo.com.br. ORCID: http://orcid.org/0000-0002$\underline{2104-5131}$
} 


\section{ABSTRACT}

Objective: To understand the experience of the father and the extended family during the hospitalization of the premature newborn in the Neonatal Intensive Care Unit. Method: Qualitative, descriptive and exploratory research, carried out in a large public maternity ward in the city of Feira de Santana, Bahia, Brazil. Data were collected through semi-structured interviews, which were recorded on audio and subsequently analyzed according to Thematic Content Analysis. Results: From the speeches of 16 participants, four thematic categories were unveiled: An experience initially marked by suffering; a difficult experience in the family's routine; seeking to become stronger throughout the experience and feeling more relaxed throughout the experience. Conclusion: The experience was marked by impactful changes in family functioning domains, considering cognitive, affective and behavioral aspects, demonstrating the need for care that intentionally contemplates the family in the researched context, as well as the implementation and monitoring of the approach recommended by centered care. in the newborn and his family.

Keywords: Family; Neonatal Intensive Care Units; Neonatal Nursing; Premature; Qualitative research.

\section{RESUMEN}

Objetivo: Comprender la experiencia del padre y de la familia ampliada durante la hospitalización del recién nacido prematuro en la Unidad de Cuidados Intensivos Neonatales. Método: Investigación cualitativa, descriptiva y exploratoria, realizada en una gran maternidad pública de la ciudad de Feira de Santana, Bahía, Brasil. Los datos fueron recolectados a través de entrevistas semiestructuradas, las cuales fueron grabadas en audio y posteriormente analizadas según Análisis de Contenido Temático. Resultados: De los discursos de 16 participantes se desvelaron cuatro categorías temáticas: Una experiencia inicialmente marcada por el sufrimiento; una experiencia difícil en la rutina familiar; buscando fortalecerse a lo largo de la experiencia y sentirse más relajado durante la experiencia. Conclusión: $\mathrm{La}$ experiencia estuvo marcada por cambios impactantes en los dominios del funcionamiento familiar, considerando aspectos cognitivos, afectivos y conductuales, demostrando la necesidad de un cuidado que contempla intencionalmente a la familia en el contexto investigado, así como la implementación y seguimiento del abordaje recomendado por el cuidado centrado en el recién nacido y su familia.

Palabras clave: Enfermería Neonatal; Familia; Investigación Cualitativa; Prematuro; Unidades de Cuidados Intensivos Neonatales. 


\section{Revista Electrónica Enfermeria Actual en costa Rica}

\section{www.revenf.ucr.ac.cr}

\section{INTRODUÇÃO}

Os avanços no tratamento em unidades de terapia intensiva neonatal (UTIN) para o recém-nascido (RN) prematuro, bem como com condições que demandam cuidado especializado, reduziram sua taxa de mortalidade. Entretanto, a admissão em uma unidade neonatal configura-se sempre como um evento que pode atrapalhar a interação paisbebê, com consequências adversas para o núcleo familiar ${ }^{1}$. Nesse contexto, a família vivencia uma experiência permeada por sofrimento, insegurança, frustração, desapontamento, medo, tristeza, ansiedade, preocupação e falta de confiança na própria capacidade de cuidar do seu filho. Por isso, é primordial prestar assistência a todos os familiares e não somente ao prematuro hospitalizado ${ }^{2}$ e sua mãe.

Alguns estudos nacionais ${ }^{3,4}$ realizados com pais de RN em UTIN, por meio da aplicação da versão brasileira da Parental Stress Scale: Neonatal Intensive Care Unit (PSS: NICU), demonstraram que a alteração no papel de mãe/pai foi a subescala em que se obteve o maior nível de estresse $\mathrm{e}^{3,4} \mathrm{e}$ os itens considerados mais estressantes nessa subescala foram "Estar separada(o) do meu bebê" e "Sentir-se desamparada(o) e incapaz de proteger o meu bebê da dor e de procedimentos dolorosos" 3 .

Quanto à subescala "Aparência e o comportamento do bebê", as situações mais estressantes foram "Quando o meu bebê parecia estar sentindo dor" e "Quando meu bebê parecia triste" ${ }^{3}$. Nesta subescala, os escores mais altos de estresse foram observados em mães que não possuíam experiência prévia com prematuridade ${ }^{4}$, sendo que se destacaram dados relacionados a "Sons e imagens", "Ver uma máquina (respirador) respirar pelo meu bebê" e "O barulho repentino do alarme dos monitores"3.

É premente que profissionais de saúde que atuam em UTIN planejem ações ${ }^{3}$ e utilizem as melhores práticas relativas ao cuidado centrado na pessoa e família ${ }^{4}$, no sentido de minimizar o impacto das situações consideradas como mais estressantes, especialmente as que envolvem a alteração do papel parental, resultando em uma abordagem que favoreça o desenvolvimento da autonomia e da segurança no desempenho de tal papel ${ }^{4}$.

No entanto, não apenas os pais e o RN devem ser foco de cuidado. Sabendo-se que a família é um sistema que é abalado pelo adoecimento e hospitalização de um de seus membros, no que se refere a seus domínios de funcionamento cognitivo, afetivo e comportamental, demandando ajustes propostos pelos profissionais de saúde envolvidos no cuidado do RN em especial no cuidado intensivo.

Torna-se necessário conhecer como este momento é vivenciado pela família ampliada, oportunizar suas narrativas, reconhecendo os significados da interação destas pessoas com o contexto do cuidado intensivo neonatal, com o RN e entre si. No presente estudo, entende-se por família ampliada ou extensa aquela que engloba, além da unidade nuclear "pais e filhos" ou unidade do casal, parentes próximos ${ }^{5}$. No caso dos prematuros hospitalizados, serão aqueles familiares que entrarão em contato com seu contexto de hospitalização e com o que tem sido vivenciado por seus pais. 


\section{Revista Electrónica Enfermeria Actual en costa Rica}

A literatura destaca que os familiares apreciam a oportunidade de serem ouvidos, de falarem sobre suas vivências, ampliando os olhares sobre a experiência de hospitalização de um de seus membros na UTIN ${ }^{6}$. Entretanto, ainda são escassos estudos qualitativos brasileiros que contemplem a família nuclear (pais e filhos) e a ampliada conjuntamente, já que a maior parte envolve a figura materna para assim desvelar a experiência familiar. Tal investigação se mostra ainda mais valiosa por conta do contexto do cuidado neonatal brasileiro: em que, apesar dos avanços, muitas unidades ainda limitam a presença dos pais, não permitindo outros familiares, mantendo a mãe como a presença mais frequente e, portanto, mais estudada. Além da falta de leis que protejam, apoiem e garantam os direitos das famílias e condições mínimas para que sua presença se dê de forma adequada.

Considera-se relevante que o desenvolvimento de pesquisas com tais participantes esteja em pauta, de forma a investigar o impacto que a hospitalização do RN gera na estrutura e no funcionamento familiar de maneira mais ampla. Até o momento, evidências desta natureza estão restritas às mães, com menor enfoque sobre a experiência paterna e de avós. Isto posto, questionou-se como é a experiência do pai e de outros membros da família, pensandose no conceito de família ampliada, quando um RN prematuro demanda hospitalização em UTIN? Assim, esta pesquisa objetivou compreender a experiência de pais e da família ampliada durante a hospitalização do RN prematuro na UTIN.

\section{MÉTODO}

Trata-se de pesquisa qualitativa, descritiva e exploratória, realizada em UTIN de uma maternidade pública de grande porte na cidade de Feira de Santana, Bahia, Brasil. O hospital em questão possui oitenta e sete leitos de internamento para as puérperas, dez leitos de cuidado intensivo, oito leitos na unidade de cuidado intermediário neonatal convencional (UCINCo) e dez para a unidade de cuidado intermediário neonatal canguru (UCINCa).

As mulheres com recém nascidos hospitalizados recebem suporte da Casa da Puérpera, no próprio hospital, de forma a terem onde ficar, favorecendo seu acesso ao filho ao minimizar viagens diárias para vê-lo. Já aquelas que os filhos têm indicação clínica para tanto, são alojadas na UCINCa. Nas três unidades mencionadas, as famílias possuem acesso ao $\mathrm{RN}$ e à puérpera, embora com horários rígidos.

Os participantes foram selecionados por meio dos seguintes critérios: ser familiar de RN prematuro hospitalizado por mais de 2 dias na UTIN; ter entrado na UTIN, no mínimo, duas vezes na primeira semana de hospitalização e ausência de história familiar de recém nascidos ou outro familiar em Unidade de Terapia Intensiva. Não foram incluídos na pesquisa familiares de recém nascidos com as seguintes condições: recém nascidos com malformações congênitas, sob cuidados paliativos e que foram a óbito na primeira semana de vida. O número de participantes foi determinado pela saturação dos dados, quando as informações passaram a serem repetidas e já suficientes para responder à questão do estudo ${ }^{7}$.

A coleta de dados ocorreu de julho a dezembro de 2017. As mães não foram foco do presente estudo. Inicialmente, foram identificados pelos pesquisadores, por meio do censo diário da UTIN, o número de recém nascidos 


\section{Revista Electrónica Enfermeria Actual en costa Rica}

prematuros hospitalizados por mais de 2 dias. A seguir, as genitoras foram abordadas na Casa da Puérpera visando orientá-las quanto à realização da pesquisa, quando foram estimuladas a identificar e convidar familiares que poderiam participar. Assim, foi agendado um encontro com eles para o dia seguinte ou de acordo com suas disponibilidades.

Antes da entrada na UTIN do hospital pesquisado, os familiares foram abordados por um membro da equipe de pesquisa que lhes apresentou os objetivos do estudo, estratégias que seriam utilizadas para a coleta de dados, riscos e benefícios relacionados à participação, bem como a informação de que sua participação seria voluntária, sem qualquer implicação para a assistência recebida ao $\mathrm{RN}$ e/ou puérpera, caso não desejassem participar. Para tanto, os pesquisadores foram previamente qualificados quanto à abordagem da família, aplicação do instrumento de coleta de dados para a obtenção de dados qualitativos e os aspectos éticos elencados na Resolução no 466 , de 12 de dezembro de $2012^{8}$, do Conselho Nacional de Saúde sobre pesquisas com seres humanos.

Os familiares optaram por participar das entrevistas sempre após a saída da UTIN, tendo em vista a dificuldade de retornarem ao hospital em outra oportunidade. A coleta de dados ocorreu por meio de entrevistas semiestruturadas. Considerando os objetivos da pesquisa, foi desenvolvido um instrumento de coleta de dados composto por duas partes. A primeira delas foi desenvolvida para o registro de dados para caracterização, como idade do familiar, grau de parentesco em relação ao $\mathrm{RN}$, cor autodeclarada, número de vezes em que entrou na UTIN, bem como idade gestacional do RN ao nascimento e tempo de hospitalização no dia da entrevista. A segunda parte continha as questões norteadoras da pesquisa: Como está sendo para você a experiência de ter um membro de sua família hospitalizado na UTIN? Como o (a) senhor (a) se sentiu na (nesta) primeira semana de hospitalização? Quais apoios sua família tem recebido (ou recebeu) neste momento?

A fim de possibilitar interação atenta com o familiar, bem como evitar a perda de dados, as entrevistas foram gravadas em áudio com auxílio de um gravador digital. No intuito de acrescentar ou retirar informações, o familiar foi estimulado a ouvir a gravação de seu relato ao término da entrevista. Posteriormente, as entrevistas foram transcritas na íntegra para compor o corpus empírico da pesquisa. Em seguida, lidas exaustivamente e submetidas à Análise de Conteúdo Temática99.

Nesse processo de análise, inicialmente o material coletado foi organizado, sendo realizadas leituras flutuantes de cada uma das entrevistas. Na fase de exploração do material, trechos das entrevistas foram codificados e agrupados em núcleos de sentido semelhantes ou afins, originando, a seguir as categorias empíricas. Em seguida, foram realizadas a inferência e a interpretação dos achados ${ }^{9}$.

\section{Considerações éticas}

A pesquisa foi aprovada pelo Comitê de Ética na Pesquisa, sob Parecer n ${ }^{\circ}$ 643.668 e CAAE: 05248713.5.2002.0053. $\mathrm{O}$ anonimato quanto à identidade dos participantes foi garantido por meio de códigos para representar suas falas (E01...E16), sendo "E" referente à palavra "entrevista" e o número ao "entrevistado", conforme a sequência de 


\section{Revista Electrónica Enfermeria Actual en costa Rica}

realização das entrevistas. Para a elaboração deste artigo, foram apresentadas apenas as falas mais representativas dos participantes, em cada categoria.

\section{RESULTADOS}

Foram entrevistados 16 familiares, com entrevistas que duraram de 10 a 30 minutos. Os participantes foram em sua maioria pais (sete), com idades entre 20 e 52 anos, que se autodeclararam pardos e haviam entrado na UTIN entre duas a nove vezes. A idade gestacional dos recém nascidos, ao nascimento, variou de 28 a 34 semanas e tempo de hospitalização no cuidado intensivo por cerca de 3 a 25 dias. O Quadro 1 apresenta a caracterização de todos os participantes.

Quadro 1. Caracterização dos familiares do Recém-nascido hospitalizado - Feira de Santana, Bahia, Brasil, 2017.

\begin{tabular}{|c|c|c|c|c|c|c|}
\hline Código & $\begin{array}{c}\text { Parentesco com o } \\
\text { RN }\end{array}$ & Idade & $\begin{array}{l}\text { Cor da } \\
\text { pele }\end{array}$ & $\begin{array}{l}\text { N0. Entradas na } \\
\text { UTIN }\end{array}$ & $\begin{array}{l}\text { IG* do } \\
\text { RN }\end{array}$ & $\begin{array}{c}\text { Tempo de hospitalização } \\
\text { do RN }\end{array}$ \\
\hline E01 & Tia materna & 45 & Parda & 2 & 34 & 3 \\
\hline E02 & Pai & 20 & Pardo & 2 & 34 & 4 \\
\hline E03 & Pai & 25 & Pardo & 2 & 32 & 3 \\
\hline E04 & Pai & 23 & Preto & 4 & 34 & 4 \\
\hline E05 & Avó materna & 55 & Branca & 2 & 34 & 5 \\
\hline E06 & Avó materna & 45 & Preta & 3 & 33 & 6 \\
\hline E07 & Pai & 27 & Pardo & 7 & 34 & 5 \\
\hline E08 & Avó materna & 53 & Branca & 3 & 27 & 7 \\
\hline E09 & Pai & 31 & Pardo & 2 & 33 & 4 \\
\hline E10 & Pai & 16 & Preto & 8 & 32 & 15 \\
\hline E11 & Tia materna & 25 & Parda & 3 & 31 & 7 \\
\hline E12 & Tia materna & 23 & Preta & 2 & 33 & 4 \\
\hline E13 & Pai & 52 & Preto & 3 & 34 & 5 \\
\hline E14 & Avó materna & 41 & Parda & 6 & 28 & 25 \\
\hline E15 & Avó paterna & 52 & Branca & 9 & 34 & 9 \\
\hline E16 & Avó paterna & 42 & Parda & 8 & 32 & 20 \\
\hline
\end{tabular}

*IG: Idade gestacional ao nascimento. Fonte: Dados da pesquisa, 2017.

A análise dos dados desvelou quatro categorias temáticas: "Uma experiência inicialmente marcada pelo sofrimento"; "Uma experiência difícil na rotina da família"; "Buscando se fortalecer ao longo da experiência" e "Sentindo-se mais tranquilos ao longo da experiência”. Essas categorias, e as subcategorias que as compõem, são apresentadas a seguir. 


\section{Revista Electrónica Enfermeria Actual en costa Rica}

\section{Uma experiência inicialmente marcada pelo sofrimento}

O nascimento prematuro do $\mathrm{RN}$ e, consequentemente, sua hospitalização na UTIN mobilizou a família inicialmente em seu domínio cognitivo, por acreditar que este espaço hospitalar se configura como um local perigoso e de indivíduos gravemente adoecidos com risco iminente de morte.

"Quando eu soube que o bebê estava na UTIN... A gente fica com medo porque é muito perigoso. Falou assim de UTIN a pessoa pensa logo que alguma coisa que vai acontecer" (referindo a piora clínica do prematuro ou sua morte). (E01) [...] "Eu achava que já iria morrer. Que só iria para UTIN por causa disso. [...] Eu achava que quando uma pessoa iria para UTI era dificil voltar" [...](E05)

Considerando o início da experiência, as falas trazem questionamentos sobre se o RN terá condições de sobreviver, haja vista suas condições de nascimento. Os familiares descrevem angústia, preocupação, tristeza e a expectativa de que a qualquer momento a morte venha a acontecer.

"Essa experiência de hospitalização tem sido muita luta. Vamos para casa e pensamos. Já acordamos pensando na UTI.

Ficamos o dia todo pensando: será que vai sobreviver?" (E14)

"Quando eu soube que ia ficar na UTIN, eu senti um pouco de preocupação, porque eu queria ter ele aqui comigo. Você cria aquela expectativa de que pode ter algum problema ou alguma coisa." (E04)

"Na UTIN, primeiro eu esperava que ele não iria sobreviver." (E03)

"Era pequeno demais. Nunca vi um bebê tão pequeno. Senti tristeza porque achei que ele não sobreviveria. Eu vi um monte de bebês de 5 e 6 meses morrendo, então eu achava que meu filho não ia conseguir sobreviver. Tive medo dele morrer."

(E10)

A família do RN prematuro vivencia a hospitalização na UTIN com intenso sofrimento, marcado pela incerteza do que virá a acontecer nos dias subsequentes e devido à crença de que a qualquer momento os profissionais desta unidade poderão lhe dar notícias ruins com relação à situação clínica da criança ou de sua morte, tendo em vista sua imaturidade orgânica.

[...] "com medo de acontecer alguma coisa com a criança por causa da respiração, porque ele nasceu bem prematuro” [...] (E02)

"Durante esses dois dias eu só tinha preocupação [...] para mim, de uma hora para outra eu iria receber uma notícia ruim." (E05)

[...] "o médico falou que podia esperar qualquer coisa dele, qualquer notícia. Fiquei então com medo, e sempre que eu venho visitar volto para casa triste, com medo de perder meu filho" [...] (E10)

"Ficamos com medo do que o médico ia falar." (E16)

Como consequência da intensa perturbação cognitiva, a família percebe-se sem forças e sem preparo para agir diante da situação.

"Comecei com uma experiência negativa [...] sem condições de ajudá-la [...] e quando eu vi tão pequena, eu falei: pronto não vai voltar mesmo". (E05) "Quando eu entrei na UTIN não tive forças para ficar perto do bebê." (E14) 


\section{Revista Electrónica Enfermeria Actual en costa Rica}

Ver o RN com a saúde frágil, cercado por aparelhos e dispositivos utilizados no suporte terapêutico, trouxe aos familiares os sentimentos de choque, medo, preocupação e tristeza, pois eles associaram tal condição com a possibilidade de morte do RN e/ou de seu sofrimento.

[...] "fiquei chocada e na mesma hora falei que estava nas mãos do Senhor (Deus). Eu nunca tinha visto menino prematuro. E ainda mais cheio de aparelhos daquele jeito. Tive medo dele não resistir." (E05)

"Eu me senti triste, porque eu não esperava ver meu neto ali (na UTIN). Uma criancinha daquela ali, que nem sabe por que está no mundo [...] eu fiquei chocada." (E06)

[...] "é muito triste ver ele do jeito que ele está lá na UTIN." (E10)

[...] "é um negócio dificil [...] aí, quando eu vi minha filha, eu fiquei com o "coração partido", porque ver aquela criancinha ali (com aparelhos)" [...] (E13)

[...] "outro dia mesmo, eu perguntei à enfermeira como minha sobrinha estava e ela me disse que estava bem, ótima.

Quando minha irmã veio, que ela falou que estava toda entubada. Como é que a criança está toda entubada e está bem, está ótima?" (E12)

"Tomei um susto porque eu nunca tinha visto aquilo. Estava toda entubada [...] era muito pequena e aí a família ficou muito ansiosa." (E14)

A UTIN também foi percebida pelos familiares como um local de risco, principalmente de infecção. Para os entrevistados, o RN só estaria seguro se estivesse em sua casa, o que também representaria para eles uma situação maior de controle e tranquilidade.

[...] "ela só iria ficar boa quando saísse da UTIN. Boa é quando está nos nossos braços, mas eu já ficava mais tranquila" $[\ldots](E 05)$

[...] "eu sei que na UTIN as crianças podem pegar infecção, então fiquei pedindo a Deus que ela não pegasse nenhuma infecção." (E15)

"Todo esse período de hospitalização está sendo uma agonia, porque se tivesse tudo bem, hoje ela estaria em casa. Ai eu estaria mais tranquila, que aí a gente poderia estar perto [...] bem não está, porque não está em casa” [...] (E12)

\section{Uma experiência difícil na rotina da família}

A hospitalização faz a família colocar o RN como prioridade, por considerar-se responsáveis pelo seu cuidado e pelo da puérpera. Assim, os familiares relataram que tiveram que modificar sua rotina, sendo que alguns renunciaram a oportunidades profissionais para estarem mais próximos da situação. Ademais, existem demandas relacionadas a outras crianças da família, que também necessitam de cuidados enquanto seus responsáveis legais estiverem no hospital, ficando com vizinhos durante este tempo de hospitalização.

"Esse periodo de hospitalização está me atrapalhando muito, porque eu tenho que deixar minha filha com a vizinha para vir ao hospital" [...] (E12)

"Essa situação está sendo chata [...] por estar todos os dias vindo aqui, não posso começar a trabalhar. Aí os trabalhos que vêm. Não posso pegar (o trabalho), porque tenho que estar aqui" (E10) 


\section{Revista Electrónica Enfermeria Actual en costa Rica}

Os depoimentos dos familiares também abordam que o distanciamento geográfico de seu domicílio em relação à unidade, bem como os horários rígidos de entrada da família na UTIN, são fatores que tornaram a experiência mais difícil. Além disso, a maioria dos entrevistados não residia no município da unidade neonatal estudada, o que demandou maior tempo de viagem e gastos adicionais com transporte ao longo da hospitalização do RN.

\section{[...] "a familia se organizou. "Tá” um... meio assim... difícil sobre o dinheiro, porque nós moramos longe. Não moramos aqui. Moramos em outra cidade." (E09)}

[...] “agora, aqui no hospital é dificil, porque tem horário pra entrar. Ai fica dificil, muito ruim” [...] (E12)

"Esse periodo de hospitalização está me atrapalhando só um pouco, por isso eu só pude visitá-la umas três vezes." (E11)

O processo de hospitalização leva o familiar a vivenciar preocupações e tensões diárias, tendo em vista limitações de acesso a informações que considerem mais fidedignas sobre o que está acontecendo.

"Eu fiquei muito preocupada porque não tinha informações sobre o bebê." (E05)

"Eu fiquei tão nervosa e preocupada, porque ninguém me falava nada sobre o bebê." (E11)

Esse contexto, faz com que decidam buscar informações de forma mais ativa, mobilizando-se para estarem presentes diariamente no hospital, no intuito de entender com mais clareza o que está acontecendo.

[...] "aí para ficar vindo para aqui, por querer notícia. Eu queria saber como é que está. Mesmo que quando a gente está em casa e o povo (os familiares) liga e falam como está, mas a gente quer ver, para ver se está daquele jeito mesmo, se está bem mesmo." (E12)

"Nós temos que vir para o hospital de qualquer maneira, pois caso contrário como é que vamos saber notícias?" (E13)

Assim, a família reorganiza-se na busca de algumas alternativas viáveis para acompanhar mais de perto a hospitalização, por entenderem que são importantes na rede de apoio tanto para a puérpera como para o RN.

"As irmãs dela vêm para o hospital ficar com ela." (E02)

"Quem mais vem ficar com ela é a sogra. Durante o tempo que eu vim, eu fiquei dando para ela a esperança de que a menina vai melhorar e de que vai sair da UTIN." (E11)

"A família toda está se apoiando e apoiando ela (a puérpera), por meio de conversas, dizendo que vai ficar tudo bem."

\section{Buscando se fortalecer ao longo da experiência}

Ter um membro da família hospitalizado na UTIN fez a família sentir-se sem forças para enfrentar e superar a experiência. Por isso, relatam recorrer à religiosidade, solicitando apoio a um ente sagrado, como recurso para vivenciar o que foi, inicialmente, muito difícil e se fortalecer.

“A gente sempre busca forças em Deus, né? Pede a Deus para dar tudo certo. E, graças a Deus, deu tudo certo, né?” (E01)

Ademais, na percepção da família, ao entregar a vida da criança nas mãos de Deus e estando a situação sob controle divino, eles poderiam vivenciar a hospitalização com mais tranquilidade. 


\section{Revista Electrónica Enfermeria Actual en costa Rica}

"Entreguei a Deus e fiquei tranquila." (E04)

[...] "eu entrego minha neta em primeiro lugar nas mãos de Deus" [...] (E14)

"Deus está no controle e eu estou orando. Não cai uma folha da árvore, se não for da permissão de Deus. Ele sabe de todas as coisas." (E06)

A crença de que Deus poderia ajudá-los a acreditar que tudo seria logo resolvido, com um resultado satisfatório, foi marcante nas entrevistas.

"Eu fiquei pedindo a Deus para que minha sobrinha saísse da UTIN rápido. Que ela saísse dos aparelhos. [...] Com fé em Deus, isso vai ser rápido. Eu pedi a Deus para ela (sobrinha) sair com vida da UTIN” [...] (E11)

[...] "estamos orando muito para que ela (bebê) sai logo da UTIN." (E12)

"Eu falei: "Jesus, Deus sabe de todas as coisas. [...] eu espero que Deus dê a vitória a gente, que a gente possa sair com ele daqui." (E16)

Apesar de entender que a imaturidade orgânica se relaciona a riscos durante a hospitalização na UTIN, os entrevistados, percebendo a evolução clínica do prematuro como estar "lutando pela vida", relataram que se mobilizaram, demonstraram esperança quanto à recuperação clínica e consequente alta, além de afirmarem que encorajaram também o bebê e a puérpera.

“Então, viu que é uma criança que está buscando a vida. Ela está tentando sobreviver também. Então, eu fiquei com um final feliz" [...] (E08)

[...] "ele (o bebê) está lutando pela vida. Ele é muito forte!" (E16)

"Durante o tempo que eu vim, eu fiquei dando para ela (a puérpera) a esperança de que a menina vai melhorar e de que vai sair da UTIN." (E11)

"A expectativa daqui pra frente é eu a ver vencer. Foi por isso que eu coloquei o nome dela de Maria Vitória. Fui eu que escolhi o nome dela." (E14)

[..] "hoje, o que eu espero é que ela se recupere logo e vá para casa." (E15)

\section{Sentindo-se mais tranquilos ao longo da experiência}

O alívio inicial apareceu na experiência dos familiares ao serem informados de que o RN estava bem.

“Agora eu estou mais aliviada. Eu já a vi (a puérpera), ela disse que o neném está bem." (E01)

[...] "mas até agora dizem (os profissionais de saúde) que está tudo bem." (E03)

Ademais, ao entrar na UTIN e constatar a melhora clínica do RN, por meio do contato físico e observação de suas reações, os familiares passaram a acreditarem que a situação estava se resolvendo, o que eles reconheceram como uma boa evolução clínica e "luta para viver" que foi travada pelo RN.

[...] "já mexo nela, ela já se movimenta. Isso me deixa mais tranquila e feliz." (E05)

"Eu já peguei na mãozinha dela. Ela mexeu. Foi uma alegria vê-la bem e se recuperando.” (E15) 


\section{Revista Electrónica Entermeria actual en costa Rica}

"Estou vendo que o bebê está vencendo e que está muito mudada." (E14)

[...] "senti um alívio, de ver que está com saúde, melhorando e cada vez mais que você chega aqui, tem uma resposta cada vez melhor" [...] (E07)

[...] "mas eu estou mais aliviando por sentir que ela (o bebê) está com um pouquinho de saúde boa” [...] (E13)

Ao ver o prematuro clinicamente bem, sem necessidade de suporte dos aparelhos utilizados na UTIN e sem medicamentos, os entrevistados demonstraram-se mais felizes diante da possibilidade alta da UTIN.

“Agora estou tranquila e feliz de vê-la sem aparelho nenhum, sem medicamento nenhum” [...] (E05)

[...] "ela está bem. Está se desenvolvendo bem sem os aparelhos." (E07)

"Fico mais tranquilo por ele está bem, porque não está mais com medicamentos e entubado." (E10)

"Ela já está sem os aparelhos. [...] Se não for muito, até a próxima semana ela já pode sair. Eu espero que não demore."

O foco na alta hospitalar é percebido nos depoimentos quando os familiares mencionam o ganho ponderal do RN prematuro, o que para eles foi uma experiência tranquilizadora, associada ao fim do sofrimento inicial.

[...] "mas agora ele está melhor. Está estável, só está esperando ganhar mais peso." (E10)

"Estamos aqui só esperando o peso dela ficar ideal para poder ir para casa. Só falta ganhar mais uns quilinhos para liberar" $[\ldots]($ E11)

Ao longo da hospitalização na UTIN, quando o familiar passa a identificar a recuperação clínica do prematuro, menciona a unidade não mais como um local de morte, mas sim onde se potencializa a vida, sendo importante para a recuperação da saúde, o que mobilizou os familiares a se sentirem mais tranquilos diante a experiência.

[...] "eu já sei que para morrer tanto basta está na UTI ou não. Agora, eu fiquei mais tranquila, que eu sei que ali não é caso de morte. É caso de recuperação de saúde [...] lá não é caso de morte é caso de vida. Se alguma pessoa da minha família entrar na UTI, eu vou aconselhar a família que lá não é caso de morte é caso de saúde, recuperar mesmo." (E05) "Hoje foi uma experiência positiva, mas no começo eu não pensava assim.[...] começou a ficar experiência positiva quando começou a se recuperar porque ficou lá (UTIN)." (E10)

Ao longo dessa experiência, as famílias desenvolvem confiança nos profissionais de saúde. Além disso, reconhecem na equipe de Enfermagem a responsabilidade pela continuidade do cuidado oferecido ao RN prematuro.

"Eu entreguei minha neta [...] em segundo lugar nas mãos dos médicos e das enfermeiras. Porque os médicos, quando saem, quem fica são as enfermeiras." (E14)

\section{DISCUSSÃO}




\section{Revista Electrónica Enfermeria Actual en costa Rica}

A experiência da família nuclear, aqui representada pelo pai e família ampliada, representada por tias e avós, diante da hospitalização do RN prematuro foi marcada por mudanças nos domínios cognitivo, afetivo e comportamental. Neste contexto, a experiência do pai e da família ampliada será retratada como dos familiares.

Considerando a categoria "Uma experiência inicialmente marcada pelo sofrimento", verifica-se que a UTIN foi considerada como um ambiente assustador, causador de sofrimento ${ }^{10}$, altamente estressante ${ }^{3,4,11,12}$, desencadeador de incertezas com relação ao que viria a acontecer ${ }^{10,12}$, bem como representante do risco iminente de morte do RN prematuro $^{13,14,15}$.

Ademais, a UTIN também não representou para os familiares um ambiente adequado para a recuperação clínica do RN prematuro, por ser percebido como um local inseguro, com risco de infecção e repleto de aparelhos como os sistemas de ventilação pulmonar mecânica, utilizados nos casos de agravamento do quadro clínico do $\mathrm{RN}^{13}$.

A UTIN tem como característica ser um ambiente com inúmeras tecnologias de suporte à vida do RN, com o emprego de procedimentos comuns e rotineiros para os profissionais de saúde, mas que são desconhecidos por muitos familiares ${ }^{16}$, principalmente para aqueles que vivenciam a experiência pela primeira vez. A fala dos participantes denota a limitação do profissional de saúde em compreender a perspectiva da família, o que faz com que mantenha sua perspectiva técnica ao se referir à condição clínica do RN e dispositivos utilizados, sem pensar sobre a repercussão desse tipo de abordagem.

A experiência foi considerada difícil também diante da possibilidade de mudanças no quadro clínico do RN, devido à sua fragilidade, gerando preocupações constantes aos familiares quanto ao futuro da criança ${ }^{2,17}$, preocupações relativas à sua situação $0^{2,18}$. Nesse processo, como em outros estudos, os familiares vivenciaram o medo da admissão do RN prematuro na UTIN ${ }^{10,12,17} \mathrm{e}$ de sua morte ${ }^{2,18}$. Choraram muitas vezes ${ }^{17}$, demonstraram intensa ansiedade ${ }^{18} \mathrm{e}$ angústia $^{12,17}$, pois, a qualquer momento, o quadro clínico da criança poderia se agravar. Assim, os relatos demonstram que, no domínio afetivo, a experiência do sistema familiar foi marcada por intenso sofrimento ${ }^{10}$.

Diante da experiência inicial, os familiares sentiram-se sem recursos externos ou internos da própria família e despreparados para enfrentar a situação $0^{6}$, o que se traduziu com falas de que não se sentiam adequados para ajudar na recuperação da criança ${ }^{16}$, sentindo-se impotentes ${ }^{10,17}$, tristes ${ }^{12}$, sem forças, vivenciando intenso sentimento de vulnerabilidade da família.

A vulnerabilidade familiar é descrita pela condição de hospitalização e doença de um filho, desencadeando sentimento de ameaça em sua autonomia familiar e colocando o sujeito sob a pressão da doença, da equipe profissional e da própria família ${ }^{19}$. A incerteza gerada pela doença, temor do resultado, ameaça real de morte, alteração na rotina familiar, conflitos com a equipe profissional, marcada pela falta de diálogo são atributos definidores relacionados à vulnerabilidade ${ }^{19}$. A ameaça à autonomia representa o significado de vulnerabilidade para a família nesse contexto ${ }^{19}$. 


\section{Revista Electrónica Enfermeria Actual en costa Rica}

Considerando a categoria "Uma experiência difícil na rotina da família", os relatos também desvelam que a hospitalização do RN alterou a estrutura do sistema familiar, desestruturando sua rotina e dinâmica de funcionamento ${ }^{2,13}$. Neste sentido, esta experiência foi percebida como difícil de ser enfrentada, pois os membros da família precisaram se locomover diariamente para estarem no ambiente hospitalar, mesmo precisando trabalhar em meio à situação ${ }^{17}$. Todo este movimento do sistema familiar foi decorrente do desejo expresso de manter proximidade ao $\mathrm{RN}$ e oferecimento de suporte à puérpera ao longo da experiência ${ }^{13}$. Além disso, padrões familiares, a exemplo da alimentação, sono e repouso, são profundamente alterados mediante adaptações realizadas na tentativa conciliá-los às atividades cotidianas e à permanência no hospital².

Por conta desses achados, considera-se imprescindível identificar a rede de apoio dos pais para auxiliá-los no enfrentamento da hospitalização do RN. O apoio oferecido pelos demais familiares ${ }^{6,10,15}$ configura-se como uma fonte de força, pois durante e após as idas ao hospital, podem relatar seus medos e dúvidas, bem como vivenciar momentos de prazer e relaxamento, minimizando o foco em preocupações e angústias ${ }^{7}$, mesmo que temporariamente. Para tanto, essa rede de apoio deve ser reconhecida pela equipe de saúde e ter sua atuação facilitada.

Esta é uma das estratégias que possibilitam cuidar da família como um todo, considerando a família nuclear e a ampliada, oferecendo-lhes suporte e mantendo-os em contato durante a hospitalização, de forma que possam também ser fonte de apoio uns aos outros, inclusive por meio de palavras ou conversas que auxiliem os pais do RN a não desistirem ou sucumbirem à situação vivenciada ${ }^{10}$.

A equipe envolvida nos cuidados ao RN também é considerada como uma fonte de amparo ${ }^{6,15,18-20}$, quando aliviam tensões e ansiedade da família, gerando sentimentos de esperança, conforto e confiança ${ }^{21,22}$. Assim, seria interessante a organização de grupos de suporte, com coordenação dos profissionais da unidade, em que famílias que vivenciam a experiência de hospitalização de um RN em UTIN possam compartilhar suas experiências, de forma que que pais e familiares percebam que não se trata de uma vivência exclusiva deles, bem como identifiquem estratégias de enfrentamento.

Nestes encontros os familiares podem compartilhar ou repensar forças e recursos utilizados no enfrentamento de experiências estressantes, bem como poderiam identificar que também possuem alguns deles, passando a implementá-los ${ }^{22}$. Nesse grupo também podem identificar o suporte de profissionais de saúde sensíveis às suas demandas, enquanto os primeiros utilizariam elementos identificados no gruo em seus planos de cuidados da família.

A categoria "Buscando se fortalecer ao longo da experiência" traz depoimentos que denotam o quanto os familiares buscaram se fortalecer por meio da fé, na crença de que um ser superior, Deus, que poderá resolver a situação vivenciada, o que lhes deu esperança, conforto e tranquilidade para acreditar na possibilidade de recuperação clínica da criança ${ }^{2,10,15,17,23} \mathrm{em}$ um futuro próximo. O que também denota a relevância de oportunizar espaços físicos para 


\section{Revista Electrónica Enfermeria Actual en costa Rica}

expressão da religiosidade no hospital, como capelas, além da presença de pastores, padres e outros líderes religiosos que se relacionem às necessidades da família.

Os relatos que desvelaram a categoria "Sentindo-se mais tranquilos ao longo da experiência" trazem a percepção de que, mesmo frente à prematuridade e aos riscos inerentes à hospitalização sob cuidados intensivos, o prematuro se mostrava em processo de melhora clínica. Além da confiança que desenvolveram pela equipe de saúde. O que os mobilizou e fortaleceu sua esperança quanto a desfechos bons, com consequente possibilidade de alta hospitalar. Tal percepção levou-os a se sentirem aliviados e a passarem a perceber a UTIN como necessária para a recuperação, um ambiente menos assustador e promotor de cuidado. Esses achados também reforçam a necessidade de a equipe de saúde investigar como a família está percebendo o quadro clínico e a interação com os profissionais.

Assim, é fundamental inserir a família como uma unidade que demanda cuidados dos profissionais de saúde durante a hospitalização de recém nascidos em UTIN, fortalecendo o Cuidado Centrado na Pessoa e Família (CCFC). Essa abordagem reconhece a relevância da inclusão da família nos cuidados e na tomada de decisão, garantindo dignidade e respeito. Além disso, tal abordagem identifica e reforça a competência parental, investiga e valoriza os sentimentos da família, bem como visa o estabelecimento de vínculo entre equipe e família ${ }^{20}$.

Neste sentido é necessário conhecer as demandas de informação das famílias, o que poderá auxiliar na reorganização da prática profissional, aprimorando o cuidado prestado e inserindo-as como parte efetiva do cuidado nas unidades neonatais, de modo que a parceria seja fortalecida, o que pode tornar a experiência de hospitalização do RN menos traumática possível ${ }^{24}$.

Para tanto, garantir o livre acesso dos pais às informações e à criança, incluindo-os nas discussões clínicas, tornaos parte da equipe que promove o cuidado e eles deixam de serem vistos apenas como "visitantes" ou "acompanhantes". Informações claras e fidedignas ao quadro clínico da criança, reconhecendo a importância do envolvimento dos pais e de pessoas significativas para eles, colaboram para uma melhor estrutura e bem-estar da família ao longo da hospitalização ${ }^{25}$.

\section{CONCLUSÕES}

A experiência da família no contexto da hospitalização de um RN em UTIN é marcada por profundas alterações nos domínios de funcionamento familiar, considerando aspectos cognitivos, afetivos e comportamentais. Considerando o relato de 16 familiares, tal experiência foi desvelada em quatro categorias temáticas: "Uma experiência inicialmente marcada pelo sofrimento"; "Uma experiência difícil na rotina da família"; "Buscando se fortalecer ao longo da experiência" e "Sentindo-se mais tranquilos ao longo da experiência".

A experiência foi marcada por sofrimento, declarado por meio de alguns sentimentos como medo, incerteza, insegurança e tristeza. O que se relacionou à condição clínica da criança e à percepção sobre os recursos de suporte à sua vida. Além disso, a hospitalização do RN foi vivenciada como algo que inicialmente desestruturou a família, mas que também mobilizou seus membros para estarem mais próximos da experiência e entre si, além de acionarem 


\section{Revista Electrónica Enfermeria Actual en costa Rica}

recursos religiosos para enfrentar a situação. Mediante a percepção de recuperação clínica da criança, os familiares sentiram-se fortalecidos, mudando a forma de significar a situação, identificando a vivência de momentos de esperança, com crença de que a situação logo seria resolvida.

Os dados apontam para a premência de um cuidado neonatal que contemple a família e não apenas o RN, no que se refere às demandas cognitivas, afetivas e comportamentais, o que vai ao encontro da implementação e manutenção do Cuidado Centrado na Pessoa e Família (CCPF). Também mostram a necessidade de desenvolver estudos de melhoria de qualidade que investiguem e acompanhem os aspectos subjetivos do cuidado neonatal, considerando programas para instrumentalização de estudantes e profissionais de saúde no que se refere a conhecimento e habilidades necessários ao CCPF.

Esta pesquisa tem como limitação o fato de que os dados não são generalizáveis, visto que contemplaram um único cenário de cuidado neonatal e suas singularidades. No entanto, considerando as particularidades locais das unidades neonatais (UTIN, UCINCo e UCINCa) do hospital em questão e do grupo social entrevistado, consideramos a possibilidade de sua generalização para este contexto.

\section{Declaração de conflito de interesse}

Os autores declaram não haver conflito de interesse.

\section{Agradecimentos}

Agradecemos ao Conselho Nacional de Desenvolvimento Científico e Tecnológico - CNPq, pelo apoio para o desenvolvimento da pesquisa por meio do Processo 478047/2013-4.

\section{REFERÊNCIAS BIBLIOGRÁFICAS}

1. Araki S, Saito T, Ichikawa S, Saito K, Takada T, Noguchi S, et al. Family-Centered Care in Neonatal Intensive Care Units: Combining Intensive Care and Family Support. J UOEH. 2017; 39(3): 235-240. DOI: https://doi.org/10.7888/juoeh.39.235.

2. Lima VF, Mazza VA, Mór LM, Pinto MNGR. Vivência dos familiares de prematuros internados em unidade de terapia intensiva neonatal. REME - Rev Min Enferm. 2017; 21: e-1026. DOI: https://doi.org/10.5935/14152762.20170036 .

3. Kegler JJ, Neves ET, Silva AM, Jantsch LB, Bertoldo CS, Silva JH. Estresse em pais de recém-nascidos em uma Unidade de Terapia Intensiva Neonatal. Esc Anna Nery. 2019; 23(1): e20180178. DOI: https://doi.org/10.1590/2177-9465-EAN-2018-0178

4. Fróes GF, Mendes ENW, Pedroza GA, Cunha MLC. Estresse experimentado por mães de recém-nascidos prétermo em unidade de terapia intensiva neonatal. Rev Gaúcha Enferm. 2020; 41(esp): e20190145. DOI: https://doi.org/10.1590/1983-1447.2020.20190145.

5. Estatuto da criança e do adolescente. Brasília: Senado Federal, Coordenação de Edições Técnicas; 2017. 


\section{Revista Electrónica Enfermeria Actual en costa Rica}

6. Fernandes NGV, Silva BEM. Vivência dos pais durante a hospitalização do recém-nascido prematuro. Rev Enf Ref. 2015; 4(4): 107-115. DOI: http://dx.doi.org/10.12707/RIV14032

7. Fontanella BJB, Luchesi BM, Saidel MGB, Ricas J, Turato ER, Melo DG. Amostragem em pesquisas qualitativas: proposta de procedimentos para constatar saturação teórica. Cad Saúde Pública. 2011; 27(2): 38994. DOI: https://doi.org/10.1590/S0102-311X2011000200020

8. Ministério da Saúde. Conselho Nacional de Saúde. Resolução 466 de 12 de dezembro de 2012. Brasil: Ministério da Saúde; 2013. Disponível em: http://conselho.saude.gov.br/resolucoes/2012/Reso466.pdf

9. Bardin L. Análise de conteúdo. São Paulo: Edições 70; 2011.

10. Moraes ES, Mendes-Castillo AMC. The experience of grandparents of children hospitalized in Pediatric Intensive Care Unit. Rev Esc Enferm USP. 2018; 52: e03395. DOI: http://dx.doi.org/10.1590/S1980220X2017040003395

11. Baía I, Amorim M, Silva S, Kelly-Irving M, de Freitas C, Alves E. Parenting very preterm infants and stress in Neonatal Intensive Care Units. Early Hum Dev. 2016; 101:3-9. DOI: https://doi:10.1016/j.earlhumdev.2016.04.001

12. Fowler C, Green J, Elliott D, Petty J, Whiting L. The forgotten mothers of extremely preterm babies: A qualitative study. J Clin Nurs. 2019; 28(11-12): 2124-2134. DOI: https://doi:10.1111/jocn.14820

13. Santos LM, Silva CLS, Santana RCB, Santos VEP. Vivências paternas durante a hospitalização do recémnascido prematuro na Unidade de Terapia Intensiva Neonatal. Rev Bras Enferm. 2012; 65(5): 788-794. DOI: https://doi.org/10.1590/S0034-71672012000500011

14. Santos LM, Oliveira IL, Passos SSP, Santana RCB, Silva JD, Lisboa SD. Mudanças familiares decorrentes da hospitalização do prematuro em cuidados intensivos: um estudo com puérperas. Rev Baiana Enferm. 2013; 27(3): 230-238. DOI: http://dx.doi.org/10.18471/rbe.v27i3.8684

15. Oliveira K, Veronez M, Higarashi IH, Corrêa DAM. Vivências de familiares no processo de nascimento e internação de seus filhos em UTI neonatal. Esc. Anna Nery. 2013; 17(1): 46-53. DOI: https://doi.org/10.1590/S1414-81452013000100007

16. Antunes BS, Paula CC, Padoin SMM, Trojahn TC, Rodrigues AP, Tronco CS. Internação do recém-nascido na Unidade Neonatal: significado para a mãe. Rev Rene. 2014; 15(5): 796-803. DOI: https://doi.org/10.15253/2175-6783.2014000500009

17. Fermino V, Mattos K, Emidio SCD, Mendes-Castillo AMC, Carmona EV. Sentimentos paternos acerca da hospitalização do filho em unidade de internação neonatal. REME - Rev Min Enferm. 2020; 24: e-1280. DOI: https://doi.org/10.5935/1415-2762.20200009

18. Tronco CS, Padoin SMM, Paula CC, Rodrigues AP, Terra MG, Aldrighi JD. "Não esperava que nascesse antes" - Vivência materna diante da internação na unidade de terapia intensiva neonatal. Cogitare Enferm. 2015; 20(1): 53-59. DOI: http://dx.doi.org/10.5380/ce.v20i1.38141

19. Pettengill MAM, Angelo M. Vulnerabilidade da família: desenvolvimento do conceito. Rev Latino-am Enfermagem. 2005; 13(6): 982-8. Disponível em: https://www.scielo.br/pdf/rlae/v13n6/v13n6a10.pdf 


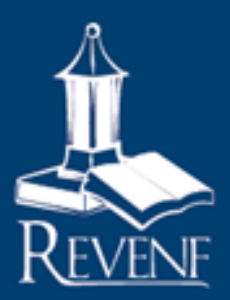

\section{Revista Electrónica Enfermeria Actual en costa Rica}

20. Serlachius A, Hames J, Juth V, Garton D, Rowley S, Petrie KJ. Parental experiences of family-centred care from admission to discharge in the neonatal intensive care unit. J Paediatr Child Health. 2018; 54(11): 1227 1233. DOI: https://doi.org/10.1111/jpc. 14063

21. Anjos LS, Lemos DM, Antunes LA, Andrade JMO, Nascimento WDM, Caldeira AP. Percepções maternas sobre o nascimento de um filho prematuro e cuidados após a alta. Rev Bras Enferm. 2012; 65(4): 571-7. DOI: https://doi.org/10.1590/S0034-71672012000400004

22. Balbino FS, Yamanaka CI, Balieiro MMFG, Mandetta MA. Parent's support group as a transforming experience for families at a neonatal unit. Esc Anna Nery. 2015; 19(2): 297-302. DOI: https://doi.org/10.5935/1414-8145.20150040

23. Soares RLSF, Christoffel MM, Rodrigues EC, Machado MED, Cunha AL. Ser pai de recém-nascido prematuro na unidade de terapia intensiva neonatal: da parentalidade a paternidade. Esc Anna Nery. 2015; 19(3): 409-16. DOI: https://doi.org/10.5935/1414-8145.20150054

24. Lima VF, Mazza VA. Necessidades de informações das famílias sobre saúde/doença dos prematuros em unidade de terapia intensiva neonatal. Texto Contexto Enferm. 2019; 28: e20170474. DOI: https://doi.org/10.1590/1980-265x-tce-2017-0474

25. Craig JW, Glick C, Phillips R, Hall SL, Smith J, Browne J. Recommendations for involving the family in developmental care of the NICU baby. $J$ Perinatol. 2015; 35(Suppl 1): S5-S8. DOI: http://dx.doi.org/10.1038/jp.2015.142 